\title{
Factors modifying the risk for developing acute skin toxicity after whole-breast intensity modulated radiotherapy
}

Sofie De Langhe1, Thomas Mulliez², Liv Veldeman², Vincent Remouchamps ${ }^{3}$, Annick van Greveling², Monique Gilsoul ${ }^{3}$, Eline De Schepper ${ }^{1}$, Kim De Ruyck', Wilfried De Neve ${ }^{2}$ and Hubert Thierens ${ }^{1 *}$

\begin{abstract}
Background: After breast-conserving radiation therapy most patients experience acute skin toxicity to some degree. This may impair patients' quality of life, cause pain and discomfort. In this study, we investigated treatment and patient-related factors, including genetic polymorphisms, that can modify the risk for severe radiation-induced skin toxicity in breast cancer patients.

Methods: We studied 377 patients treated at Ghent University Hospital and at ST.-Elisabeth Clinic and Maternity in Namur, with adjuvant intensity modulated radiotherapy (IMRT) after breast-conserving surgery for breast cancer. Women were treated in a prone or supine position with normofractionated $(25 \times 2$ Gy) or hypofractionated $(15 \times 2.67$ Gy) IMRT alone or in combination with other adjuvant therapies. Patient- and treatment-related factors and genetic markers in regulatory regions of radioresponsive genes and in $L / G 3, M L H 1$ and XRCCC genes were considered as variables. Acute dermatitis was scored using the CTCAEv3.0 scoring system. Desquamation was scored separately on a 3-point scale (0-none, 1-dry, 2-moist).

Results: Two-hundred and twenty patients (58\%) developed G2+ dermatitis whereas moist desquamation occurred in 56 patients (15\%). Normofractionation (both $p<0.001$ ), high body mass index (BMI) ( $p=0.003$ and $p<0.001$ ), bra cup size $\geq D(p=0.001$ and $p=0.043)$ and concurrent hormone therapy $(p=0.001$ and $p=0.037)$ were significantly associated with occurrence of acute dermatitis and moist desquamation, respectively. Additional factors associated with an increased risk of acute dermatitis were the genetic variation in MLH1 rs1800734 ( $p=0.008)$, smoking during RT ( $p=$ $0.010)$ and supine IMRT ( $p=0.004)$. Patients receiving trastuzumab showed decreased risk of acute dermatitis $(p<0.001)$.

Conclusions: The normofractionation schedule, supine IMRT, concomitant hormone treatment and patient related factors (high BMl, large breast, smoking during treatment and the genetic variation in MLH1 rs1800734) were associated with increased acute skin toxicity in patients receiving radiation therapy after breast-conserving surgery. Trastuzumab seemed to be protective.
\end{abstract}

Keywords: Acute skin toxicity, Breast cancer, Genetic polymorphisms, Large breast size, Radiotherapy

\footnotetext{
*Correspondence: Hubert.Thierens@UGent.be

'Department of Basic Medical Sciences, Ghent University, Proeftuinstraat 86,

9000 Ghent, Belgium

Full list of author information is available at the end of the article
}

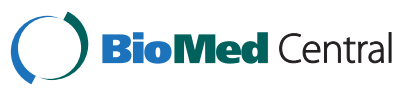

(c) 2014 De Langhe et al.; licensee BioMed Central Ltd. This is an Open Access article distributed under the terms of the Creative Commons Attribution License (http://creativecommons.org/licenses/by/2.0), which permits unrestricted use, distribution, and reproduction in any medium, provided the original work is properly credited. The Creative Commons Public Domain Dedication waiver (http://creativecommons.org/publicdomain/zero/1.0/) applies to the data made available in this article, unless otherwise stated. 


\section{Background}

Breast-conserving therapy with the adjuvant use of radiotherapy (RT) has gained an established role in the treatment for early-stage breast cancer with excellent long-term local control and survival [1]. During or shortly after the course of breast cancer RT, a large portion of the patients will experience acute radiation dermatitis to some degree, varying from mild to brisk erythema with or without moist desquamation and occasionally ulceration of the skin [2]. There is accumulating clinical evidence that acute reactions are associated with the development of late toxicity: Lilla et al. showed that telangiectasia are in fact late sequelae of moist desquamation and acute erythema is shown to be a risk factor for poor cosmetic outcome [3-5]. Though the skin is not a dose-limiting tissue, skin toxicity is associated with impairment of patients' quality of life, causes pain and discomfort and limits activities [2,6]. The challenge is to minimize these side effects without losing efficacy of the treatment.

Over the years, many attempts have been made to reduce the number of patients experiencing acute skin toxicity and inferior cosmetic outcome by introducing improved radiation techniques, such as intensity-modulated radiotherapy (IMRT). This technique has been shown to be superior over conventional wedge-based whole breast irradiation by delivering a more homogenous dose through the breast and removing the radiation hot spots; it results in an approximately $20 \%$ reduction of the frequency of moist desquamation [6,7]. Large breast size significantly contributes to dose inhomogeneity, hot spots and toxicity $[7,8]$. The variation in clinical response is, however, only partly explained by treatment factors such as radiation dose, fractionation scheme, and concomitant therapies. Patientrelated features (e.g. bra cup size and body mass index (BMI)) also play a role together with an unknown contribution from genetic factors. Up to now there are no data available to estimate directly the heritability of clinical radiosensitivity based upon family history of radiotherapy toxicity, but it is likely to be somewhat lower than for chromosomal and cellular radiosensitivity, which have been calculated to be $58-78 \%$ [9].

Acute toxicity is initiated by depletion of acutely responding epithelial tissues and damage to microvessels [10]. Numerous studies have reported on genetic variations modifying the clinical radiosensitivity risk, predominantly in pathways based on mechanistic understanding of the radiation pathogenesis (reviewed in [11]). In the present study, single nucleotide polymorphisms (SNPs) in genes involved in major DNA repair pathways (LIG3, XRCC3, $M L H 1)$ and in regulatory regions that influence the expression levels of radioresponsive genes are considered [12-16].

To gain a better insight into the development of radiation-induced dermatitis and moist desquamation, we evaluated the association between patient and treatment features with these endpoints. The association between SNPs and the different clinical endpoints was also studied.

\section{Methods}

The study population consists of 377 breast cancer patients treated with adjuvant IMRT with curative intent after breast-conserving surgery (stage T1-3, N0-1, M0). Of them, 282 breast cancer patients were treated at the Ghent University Hospital (GUH) and 95 patients were treated at ST.-Elisabeth Clinic and Maternity (CMSE) in Namur. Patients' follow-up ranged from 1 month after the end of RT to 41 months after the end of RT (median = 18 months).

At GUH, patients were treated in prone or supine position using a multi-beam IMRT technique in supine position and a tangential 2-beam field-in-field IMRT technique in prone position as described previously [17]. The whole breast was treated with hypofractionated radiotherapy (40.05 Gy in 15 fractions [18]) with 6-MV photons of an Elekta Synergy linear accelerator (Crawley, United Kingdom). An additional photon boost of $10 \mathrm{~Gy}$ in 4 fractions to the tumour bed was given to $75 \%$ of the patients. For the prone patient setup, a unilateral breast holder (Van De Velde, Schellebelle, Belgium) and a prone breast board (Orfit Industries) were used [19]. Twenty-two patients were treated in prone position with voluntary moderate deep inspiration breath hold. At CMSE Namur, a sliding window tangential field-IMRT technique was used associated with moderate deep inspiration breath hold whenever the primary beam intersected the heart as previously described by Remouchamps et al. [20]. Patients with selfreported bra cup size $\geq \mathrm{D}$ received normofractionated radiotherapy (50.00 Gy in 25 fractions), women with bra cup size $<D$ received hypofractionation or normofractionation according to the preference of the radiation oncologist $(n=28)$. More than $90 \%$ received an additional boost of 10 Gy in 4 fractions with electron beams. Nodal irradiation was performed by a complex multi-beam IMRT or arc technique at GUH, at CMSE Namur, a one point setup with 4 beams with dynamic intensity modulation in the beams was used.

\section{Adjuvant systemic therapy}

Adjuvant hormone therapy, consisting of tamoxifen or aromatase inhibitors, was administered in most patients concomitantly with IMRT. The others received hormone therapy sequentially after IMRT. Patients who received adjuvant chemotherapy, combination of antracyclines and taxanes, completed chemotherapy before IMRT, while trastuzumab was allowed concomitantly with IMRT.

\section{Data collection}

Data on patients' medical history, tumor and treatment characteristics were collected prospectively. Table 1 gives 
Table 1 Patient characteristics for patients treated at GUH and CMSE Namur

\begin{tabular}{|c|c|c|c|}
\hline & & GUH & CMSE Namur \\
\hline & & $(n=282)$ & $(n=95)$ \\
\hline Age (years) & & & \\
\hline & Median & 57.5 & 59.0 \\
\hline & Range & $30-82$ & $35-82$ \\
\hline Bra cup size & & & \\
\hline & Small & $13(4.6)$ & $3(3.2)$ \\
\hline & & $85(30.2)$ & $33(34.7)$ \\
\hline & & $101(35.8)$ & $34(35.8)$ \\
\hline & Large & $53(18.8)$ & $16(16.8)$ \\
\hline & & $16(5.7)$ & $5(5.3)$ \\
\hline & & $7(2.5)$ & $3(3.2)$ \\
\hline & & $\mathrm{G}+\mathrm{H}$ & $1(1.0)$ \\
\hline & Missing & 5 & 0 \\
\hline $\mathrm{BMI}$ & & & \\
\hline & Median & 25.5 & 26 \\
\hline & Range & $16-50$ & $16-38$ \\
\hline & Missing & 2 & 0 \\
\hline Menstruatic & & & \\
\hline & No & 235 (83.3) & $76(80.0)$ \\
\hline & Yes & $45(16.0)$ & $18(18.9)$ \\
\hline & Missing & 2 & 1 \\
\hline $\begin{array}{l}\text { Smoking } \\
\text { during RT }\end{array}$ & & & \\
\hline & No & $244(86.5)$ & 79 (83.2) \\
\hline & Yes & $35(12.4)$ & $16(16.8)$ \\
\hline & Missing & 3 & 0 \\
\hline Diabetes & & & \\
\hline & No & $254(90.1)$ & $84(88.4)$ \\
\hline & Yes & $22(7.8)$ & $11(11.6)$ \\
\hline & Missing & 6 & 0 \\
\hline Hypertensic & & & \\
\hline & No & $196(69.5)$ & $66(69.5)$ \\
\hline & Yes & $81(28.7)$ & $29(30.5)$ \\
\hline & Missing & 5 & 0 \\
\hline Fractionatic & & & \\
\hline & Normo & 0 & $45(47.4)$ \\
\hline & Нypo & 282 & $50(52.6)$ \\
\hline & Missing & 0 & 0 \\
\hline $\begin{array}{l}\text { Treatment } \\
\text { position }\end{array}$ & & & \\
\hline & Supine & $195(69.1)$ & $95(100.0)$ \\
\hline & Prone & $87(30.9)$ & 0 \\
\hline & Missing & 0 & 0 \\
\hline
\end{tabular}

Table 1 Patient characteristics for patients treated at GUH and CMSE Namur (Continued)

\begin{tabular}{|c|c|c|c|}
\hline & & GUH & CMSE Namu \\
\hline & & $(n=282)$ & $(n=95)$ \\
\hline \multicolumn{4}{|l|}{ Boost } \\
\hline & No & $64(22.7)$ & $7(7.4)$ \\
\hline & Yes & $218(77.3)$ & 88 (92.6) \\
\hline & Missing & 0 & 0 \\
\hline \multicolumn{4}{|c|}{ Nodal irradiation } \\
\hline & No & $241(85.5)$ & 87 (80.6) \\
\hline & Yes & $41(14.5)$ & 21 (19.4) \\
\hline & Missing & 0 & 0 \\
\hline \multicolumn{4}{|c|}{$\begin{array}{l}\text { Hormonal } \\
\text { therapy }\end{array}$} \\
\hline & No & $46(16.3)$ & $25(26.3)$ \\
\hline & Concomitant & $236(83.7)$ & $7(7.4)$ \\
\hline & $\begin{array}{l}\text { Sequential } \\
\text { (after IMRT) }\end{array}$ & 0 & $63(66.3)$ \\
\hline & Missing & 0 & 0 \\
\hline \multicolumn{4}{|c|}{ Chemotherapy } \\
\hline & No & $188(66.7)$ & $55(57.9)$ \\
\hline & Yes & $94(33.3)$ & $40(42.1)$ \\
\hline & Missing & 0 & 0 \\
\hline \multicolumn{4}{|c|}{ Trastuzumab } \\
\hline & No & $257(91.1)$ & $83(87.4)$ \\
\hline & Yes & $25(8.9)$ & 12 (12.6) \\
\hline & Missing & 0 & 0 \\
\hline
\end{tabular}

an overview of the patient characteristics for patients treated at GUH and CMSE Namur.

Acute toxicity was assessed weekly during treatment and at 1-2 weeks after treatment. The reported toxicity represents the maximal reported acute toxicity, either during or after completion of IMRT. Acute dermatitis was documented according to a standard protocol using the Common Terminology Criteria for Adverse Events (CTCAE) v3.0 scoring system. This grades patients with mild erythema or dry desquamation as 1 , moderate to brisk erythema or patchy moist desquamation mostly confined to the skin folds as 2 and confluent moist desquamation as 3 . Desquamation was scored separately on a 3-point scale (0-none, 1-dry, 2-moist). Grade 2-3 toxicity was considered clinically relevant and was included in the analysis. Genomic DNA was isolated from a fresh blood sample taken before start of radiotherapy, using the Puregene genomic DNA purification kit (Gentra Systems, Minneapolis, MN). The study was approved by the local 
ethics committees (Ghent University Hospital EC 2009/ 424, EC 2009/184) and all study patients provided written informed consent.

\section{Selection of candidate genes/polymorphisms and genotyping}

Eight candidate polymorphisms were selected for genotyping (Table 2). Of these, five SNPs (rs3888929, rs4867592, rs7970524, rs12003093, rs4760658) were chosen as they putatively affect the expression levels of radiation-responsive genes directly, or by trans effects, based on genetic linkage and association analysis as described previously by Smirnov et al. The authors suggested that those regulatory variants might be able to contribute to the development of genetic tools for radiosensitivity [16]. The other SNPs were chosen based on their previous association with toxicity induced by radiotherapy or methylating agents (XRCC3 rs861539, LIG3 rs3744355, MLH1 rs1800734) [12-15]. Genotyping was performed using restriction fragment length polymorphism analyses, high resolution melting curve analyses, single base extension techniques or direct sequencing. For reproducibility control, $15 \%$ of all samples were duplicated. The concordance rate between duplicate samples was $100 \%$. Primers details are available on request. Tests for deviation from Hardy-Weinberg equilibrium, for the entire sample showed that the rs4867592 SNP had a p-value $<0.0001$ and was excluded from further analyses.

\section{Statistical analysis}

The studied endpoints were development of acute radiationinduced dermatitis (CTCAE G2+) and moist desquamation. For the clinical association analysis, univariate analysis was initially carried out to assess the relationship between patient- (age, bra cup size (A+B + C vs. $\geq D)$, BMI, menstruation, smoking during RT, diabetes, hypertension) and treatment-related factors (fractionation scheme, treatment position, boost dose to tumour bed, nodal irradiation, hormone therapy, chemotherapy and trastuzumab) and the endpoints. Patients with and without G2+ acute skin toxicity were compared by means of the Mann-Whitney test for continuous variables and the $\chi^{2}$-test for categorical variables. Power calculations were performed with Power for Genetic Association analyses [21]. For these we took into account: the incidence of dermatitis $(58 \%)$ or moist desquamation (15\%) observed in our cohort, the lowest minor allele frequency (9\%) of the considered SNPs, a probability adjusted by the number of SNPs $\left(\alpha=6.25 \times 10^{-3}\right)$ under a dominant genotypic test, and a genotype relative risk of $\geq 1.5$. This resulted in a power of $94.3 \%$ for acute dermatitis and $60.9 \%$ for moist desquamation. To assess the independent effect of each polymorphism, unconditional logistic regression analyses were performed to calculate crude ORs. The Benjamini-Hochberg (BH) procedure was used to control for multiple testing (i.e. 43 tests per endpoint: 28 genetic and 15 clinical parameter tests) to reduce the risk of finding false-positive associations. Variables with $\mathrm{p}<0.05$ were tested in a multivariate logistic regression analysis. Statistical analyses were performed using SPSS 17.0 software (SPSS Inc., Chicago, IL). R library multtest (http://www.r-project.org/) was used to perform the multiple testing analyses.

\section{Results}

Acute radiation-induced skin toxicity data were available for all 377 patients. Two-hundred twenty patients (58\%) developed G2+ dermatitis. The occurrence of dermatitis did not differ between both centres (GUH: 57\% (162/282), CSME: 61\% (58/95)). Moist desquamation (patchy or confluent) occurred in 56 patients (15\%) and differed between both centres: $10 \%$ of the patients treated at GUH and $30 \%$ of the patients treated at CMSE $(\mathrm{p}<0.001)$.

\section{Acute radiation-induced skin toxicity}

Table 3 depicts the parameters associated with acute $\mathrm{G} 2+$ dermatitis, in univariate analysis. Bra cup size $\geq \mathrm{D}$ $(\mathrm{p}<0.001)$, BMI $(\mathrm{p}<0.001)$ and smoking during $\mathrm{RT}(\mathrm{p}=$ $0.029)$ were associated with the development of $\mathrm{G} 2+$ dermatitis. Irradiation of the nodal region $(\mathrm{p}=0.006)$ and

Table 2 Characteristics of the SNPs

\begin{tabular}{|c|c|c|c|c|c|c|}
\hline Gene or gene regulator & rs number & MAF* $^{*}$ & Nucleotide substitution & Genomic location & Amino acid substitution & Reference \\
\hline LIG3 & rs3744355 & 9.1 & $G>C$ & 5'-flanking & - & {$[12,13]$} \\
\hline MLH1 & rs1800734 & 22.6 & $G>A$ & $5^{\prime}-U T R$ & - & [14] \\
\hline$X R C C 3$ & rs861539 & 39.0 & $C>T$ & Coding & Thr241Met & [15] \\
\hline PHLDA3 & rs3888929 & 30.3 & $G>A$ & Unknown & - & [16] \\
\hline$\angle C P 2$ & rs4867592 & 19.1 & $C>A$ & Unknown & - & [16] \\
\hline LTHA4 & rs7970524 & 25.1 & $\mathrm{~T}>\mathrm{C}$ & 5'-flanking & - & [16] \\
\hline NDUFB6 & rs12003093 & 23.4 & $A>G$ & Unknown & - & [16] \\
\hline$V D R$ & rs4760658 & 36.6 & $A>G$ & Intronic & - & [16] \\
\hline
\end{tabular}

*Minor allele frequency in Caucasian population. 
Table 3 Associations between patient- and therapy-related characteristics and acute G2+ dermatitis

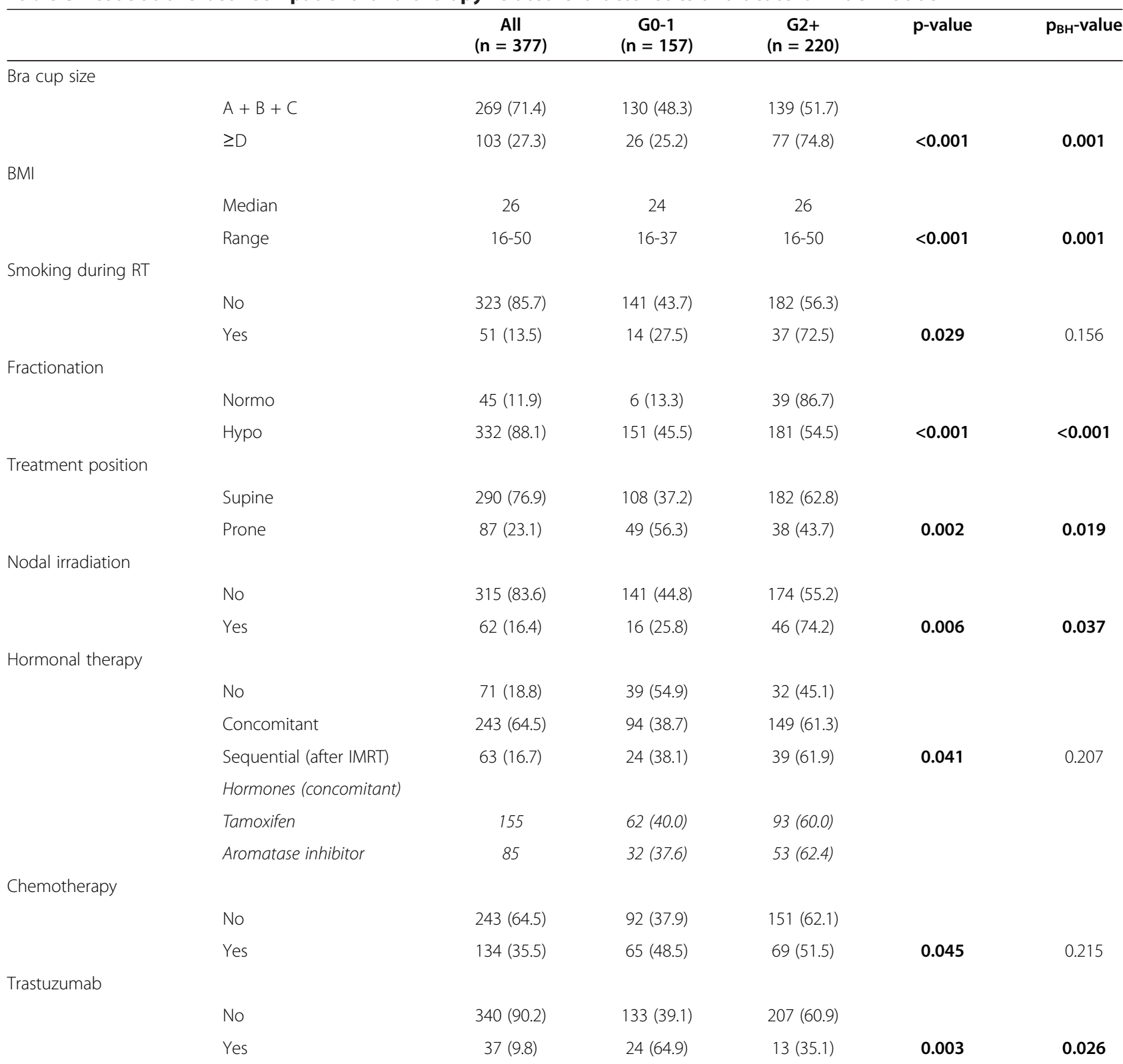

Abbreviations: G CTCAEv.3 grade, BMI Body Mass Index; $\mathrm{p}_{\mathrm{BH}}=$ corrected $\mathrm{p}$-value by Benjamini-Hochberg procedure.

Data are given as no. (\%) unless otherwise indicated. $\mathrm{P}<0.05$ is considered significant and is showed in bold.

the use of concomitant hormone therapy $(p=0.041)$ were also associated with an increased risk of acute dermatitis, with no difference in incidence between aromataseinhibitors and tamoxifen. In contrast, patients receiving trastuzumab or having received chemotherapy seem to be less prone to the development of RT-induced acute dermatitis $(\mathrm{p}=0.003$ and $\mathrm{p}=0.045$, respectively). Furthermore, patients treated with hypofractionated radiotherapy develop less dermatitis when compared to patients treated in the normofractionated regimen $(\mathrm{p}<0.001)$. And, patients treated in prone position developed less dermatitis than patients treated supine $(\mathrm{p}=0.002)$. In multivariate analysis, chemotherapy and nodal irradiation were no longer significant (Table 4).

For moist desquamation, univariate significant associations were found with bra cup size $\geq D(p<0.001)$, BMI $(\mathrm{p}<0.001)$, normofractionation $(\mathrm{p}<0.001)$, supine positioning $(p=0.002)$, concurrent hormone therapy $(p=0.004)$ and CSME center $(\mathrm{p}<0.001)$ (Table 5). In multivariate analysis (Table 6), bra cup size $\geq \mathrm{D}, \mathrm{BMI}$, fractionation and hormone therapy remained statistically significant. Treatment center was no longer significantly associated with moist desquamation due to the fact that the normofractionated schedule was only prescribed at CMSE. 
Table 4 Multivariate analysis for G2+ dermatitis and moist desquamation

\begin{tabular}{|c|c|c|c|c|}
\hline \multirow[t]{2}{*}{ Clinical/genetic factor } & \multicolumn{2}{|c|}{ Acute G2+ dermatitis } & \multicolumn{2}{|c|}{ Moist desquamation } \\
\hline & OR & p-value & OR & p-value \\
\hline Center (CMSE vs. GUH) & - & - & 3.206 & 0.158 \\
\hline BMI & 1.088 & 0.003 & 1.170 & $<0.001$ \\
\hline Bra cup size (cup $\geq D$ vs. cup $A+B+C$ ) & 2.833 & 0.001 & 2.146 & 0.043 \\
\hline Smoking (yes vs. no) & 2.711 & 0.010 & - & - \\
\hline Fractionation (hypo vs. normo) & 0.083 & $<0.001$ & 0.096 & $<0.001$ \\
\hline Treatment position (prone vs. supine) & 0.399 & 0.004 & 0.373 & 0.074 \\
\hline \multicolumn{5}{|l|}{ Hormone therapy } \\
\hline No & 1 & & 1 & \\
\hline Concomitant & 3.207 & 0.001 & 4.770 & 0.037 \\
\hline Sequential (after IMRT) & 1.003 & 0.994 & 1.078 & 0.901 \\
\hline Nodal irradiation (yes vs. no) & 1.975 & 0.100 & - & - \\
\hline Chemotherapy (yes vs. no) & 0.954 & 0.877 & - & - \\
\hline Trastuzumab (yes vs. no) & 0.177 & $<0.001$ & - & - \\
\hline \multicolumn{5}{|l|}{ MLH1 rs1800734 G > A } \\
\hline GG & 1 & & - & \\
\hline GA & 0.492 & 0.008 & - & - \\
\hline AA & 0.537 & 0.232 & - & - \\
\hline
\end{tabular}

Abbreviations: GUH Ghent University Hospital, CMSE Clinic Maternity Sainte-Elisabeth, BMI Body Mass Index, MLH1 MutL protein homolog 1.

$\mathrm{P}<0.05$ is considered significant and is showed in bold.

Table 5 Associations between patient- and therapy-related characteristics and moist desquamation

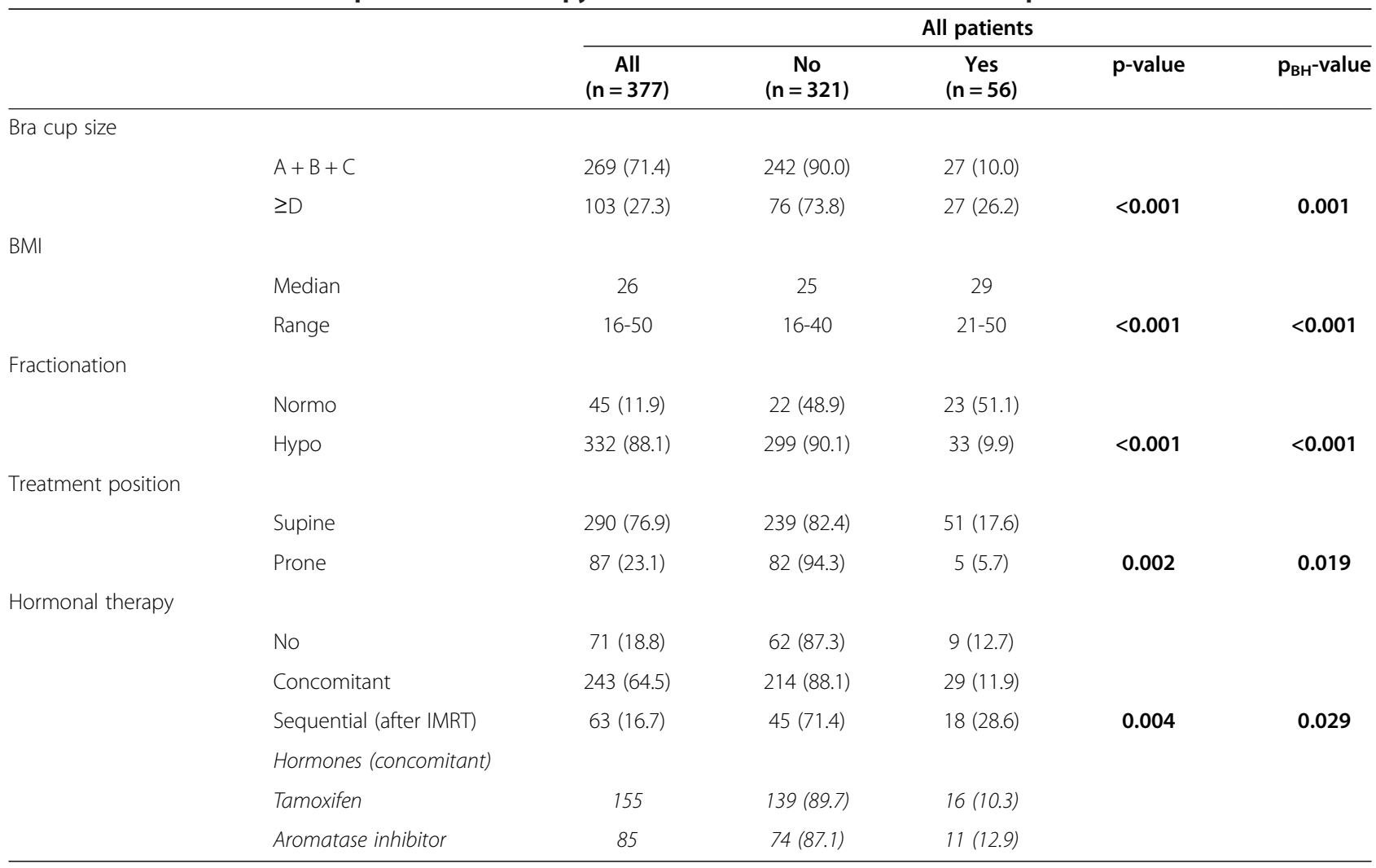


Table 6 Effect of $M L H 1$ rs1800734 on radiotherapy acute skin reactions

\begin{tabular}{|c|c|c|c|c|c|c|c|c|c|c|c|}
\hline & & \multicolumn{5}{|c|}{ Acute G2+ dermatitis } & \multicolumn{5}{|c|}{ Moist desquamation } \\
\hline & & $\begin{array}{c}\text { G0-1 } \\
(n=157)\end{array}$ & $\begin{array}{c}\mathrm{G} 2+ \\
(n=220)\end{array}$ & OR & p-value & $\overline{p_{B H}-v a l u e}$ & $\begin{array}{c}\text { No } \\
(n=321)\end{array}$ & $\begin{array}{c}\text { Yes } \\
(n=95)\end{array}$ & OR & p-value & $\mathrm{p}_{\mathrm{BH}}$-value \\
\hline \multicolumn{12}{|c|}{ MLH1 rs1800734 } \\
\hline \multirow[t]{4}{*}{$G>A$} & GG & $81(51.6)$ & $146(66.4)$ & & & & $189(58.9)$ & $38(67.9)$ & & & \\
\hline & GA & $64(40.8)$ & $60(27.3)$ & 0.52 & 0.004 & 0.029 & $110(34.3)$ & $14(25.0)$ & 0.63 & 0.172 & 0.477 \\
\hline & AA & $9(5.7)$ & $12(5.5)$ & 0.74 & 0.514 & 0.804 & $17(5.3)$ & $4(7.1)$ & 1.17 & 0.788 & 0.915 \\
\hline & Missing & $3(1.9)$ & $2(0.9)$ & & & & $5(1.6)$ & 0 & & & \\
\hline \multicolumn{2}{|c|}{ GG vs. GA + AA (dominant) } & & & 0.55 & 0.005 & 0.033 & & & 0.71 & 0.257 & 0.575 \\
\hline \multicolumn{2}{|c|}{ GG + GA vs. AA (recessive) } & & & 0.94 & 0.889 & 0.936 & & & 1.35 & 0.600 & 0.860 \\
\hline
\end{tabular}

Abbreviations: $M L H 1$ MutL protein homolog 1, $\mathrm{p}_{\mathrm{BH}}=$ corrected $\mathrm{p}$-value by Benjamini-Hochberg procedure.

Data are given as no. (\%) unless otherwise indicated. $\mathrm{P}<0.05$ is considered significant and is showed in bold.

\section{Genetic analysis}

The only significant p-value, in univariate analysis, was for acute radiation-induced dermatitis with the GA genotype of rs1800734 in the $M L H 1$ gene with a $\mathrm{BH}$-adjusted pvalue of 0.029 (Table 6). Adjusting for above mentioned factors by multivariate regression analysis had no effect on the statistically significant association. None of the other SNPs had any effect on the risk of acute skin toxicity.

\section{Discussion}

This study was performed to analyze the influence of treatment and patient-related factors on the development of acute radiation-induced skin toxicity. Bra cup size, BMI, smoking, treatment position, choice of RT schedule and the administration of adjuvant therapies seem to contribute to the variability in radiation skin toxicity. Also, the MLH1 rs1800734 SNP was found to be significantly associated with the development of acute dermatitis.

Our data support the hypothesis that acute toxicity does not increase with moderate hypofractionation [22]. In fact, the occurrence of acute skin toxicity was significantly higher among patients treated with normofractionation compared to the hypofractionated schedule. There are only few reports studying hypofractionation in overweighed or large-breasted patients [23,24]. We observe a $20 \%$ decrease in dermatitis and an even larger decrease (70\%) in moist desquamation in large-breasted patients treated in supine position with hypofractionation compared to normofractionation (data not shown). Bra cup size and BMI were also confirmed as significant risk factors for the development of acute skin toxicity, in accordance with the majority of published reports [7,8,25-27]. Both are measures of breast volume as BMI was previously found to be strongly correlated with breast volume [27]. The association between larger breast volume and toxicity is thought to be due to dose inhomogeneity, high dose regions, and the bolus effect in the inframammary and axillary regions [8]. Due to the unavailability of dose homogeneity and hot spot data for the complete dataset, we were unable to test this for the total patient population, but the hypothesis is confirmed in a subset of the population [19]. Goldsmith et al. show that dose inhomogeneity is insufficient to explain the association and other factors like the presence of more adipose tissue might also play a role [25]. In prone position, the skin creases disappear, dose homogeneity is improved and hot spots are reduced leading to a reduction in acute skin toxicity [17]. In this study, we found a decrease in radiodermatitis and moist desquamation in patients treated with prone-IMRT. Especially patients with large breast sizes are expected to have a great benefit from proneIMRT as shown by Mulliez et al. [19].

In this study, two types of adjuvant hormone therapy, tamoxifen or aromatase-inhibitors, were concurrently administered with radiotherapy to hormone receptor positive breast cancer patients. Present data show that use of hormone therapy is, regardless the type, associated with an increase in radiation-induced dermatitis. This is in accordance with a previous study investigating the effect of tamoxifen on acute skin reactions [26]. But in contrary with the COHORT randomized trial, that shows no difference between concurrent and sequential administration of letrozole; the latter was administered 3 weeks after RT when it is supposed that the radiosensitising effect of endocrine therapy is minimal [28]. Concurrent administration of trastuzumab and IMRT was found to be associated with lower rates of acute dermatitis in the present study. This finding needs to be put in perspective as it is in contradiction with the observation of a large randomized study that could not find a difference in acute toxicity [29]. Longer follow-up will be necessary to observe the effect of concurrent administration on cardiac toxicity.

Our study shows an association between the MLH1 rs1800734 SNP and lower rates of acute radiation-induced dermatitis: heterozygotes are less present in the G2+ 
dermatitis group. The SNP maps 93 base pairs upstream of the MLH1 transcription site in the core promoter, a region essential for maximum transcriptional activity [30]. The SNP was previously shown to be associated with acute myeloid leukemia after methylating chemotherapy for Hodgkin disease [15]. MLH1 gene encodes MutL protein homolog 1 which is involved in DNA mismatch repair. Suga et al. found statistically significant associations with rs3744355 in the $5^{\prime}$ flanking region of the LIG3 gene and acute radiation-induced skin reactions in the Japanese population and Murray et al. provided replicated evidence for this association in a European Caucasian population [12,13]. We, however, could not confirm this association. Smirnov et al. hypothesized that regulatory variants might be able to contribute to the development of genetic tools to predict for radiosensitivity [16]. This could not be demonstrated in our study population.

Radiation-induced dermatitis includes erythema, edema, dry and moist desquamation as symptoms of inflammation probably triggered by cell death [31]. One of the shortcomings in this study is the fact that erythema was not measured objectively with a colorimeter. As the CTCAE criteria are based on subjective scoring, the difference between mild, moderate and brisk erythema is observer-dependent. This probably explains the large number of patients developing G2+ acute dermatitis when compared to other reports. A strength of our investigation is the nearly complete data set for a relatively large number of patients enrolled. Furthermore, patient recruitment as well as clinical outcome data collection were carried out prospectively. Although the associations hold after correcting for multiple testing, the results of this study should be validated in an independent study.

\section{Conclusion}

A number of treatment and patient related factors are identified that modify the risk for the development of acute skin toxicity after whole-breast IMRT. Large bra cup, BMI, normofractionation and concomitant hormone therapy contribute to the development of moist desquamation. Patient related factors (high BMI, large breast, smoking during treatment and the genetic variation MLH1 rs1800734), choice of RT schedule and the administration of adjuvant therapies affect the development of radiodermatitis.

\footnotetext{
Abbreviations

BH: Benjamini-hochberg; BMI: Body mass index; CMSE: ST.-Elisabeth Clinic and Maternity; CTCAE: Common terminology criteria for adverse events; GUH: Ghent University Hospital; IMRT: Intensity-modulated radiotherapy; RT: Radiotherapy; SNP: Single nucleotide polymorphism.
}

\section{Competing interests}

The authors declare that they have no competing interests.

\section{Authors' contributions}

SDL participated in conception and design, the acquisition, performed the statistical analysis and interpretation of the data and drafted the manuscript. TM, LV, VR, AVG, MG and WDN participated in acquisition of the data. EDS carried out the genotyping work and helped in the statistical analysis. KDR, WDN and HT participated in the conception and design. All authors critically revised the manuscript and approved the final manuscript.

\section{Acknowledgments}

This work was supported by the Cancer Plan, Action 29 project 015, financed by the Federal Office of Health and Social Affairs, Belgium. We wish to thank Christian Defresne for his help with the toxicity recording and all study participants.

\section{Author details}

'Department of Basic Medical Sciences, Ghent University, Proeftuinstraat 86, 9000 Ghent, Belgium. ²Department of Radiotherapy, Ghent University Hospital, De Pintelaan 185, 9000 Ghent, Belgium. ${ }^{3}$ Department of Radiotherapy, Clinique et Maternité St Elisabeth, Place Louise Godin, 15, 5000 Namur, Belgium.

Received: 28 October 2013 Accepted: 18 September 2014 Published: 25 September 2014

\section{References}

1. Early Breast Canc Trialists C: Effect of radiotherapy after breast-conserving surgery on 10-year recurrence and 15-year breast cancer death: meta-analysis of individual patient data for 10801 women in 17 randomised trials. Lancet 2011, 378(9804):1707-1716.

2. Feight D, Baney T, Bruce S, McQuestion M: Putting evidence into practice: evidence-based interventions for radiation dermatitis. Clin J Oncol Nurs 2011, 15(5):481-492.

3. Tanteles GA, Whitworth J, Mills J, Peat I, Osman A, McCann GP, Chan S, Barwell JG, Talbot CJ, Symonds RP: Can cutaneous telangiectasiae as late normal-tissue injury predict cardiovascular disease in women receiving radiotherapy for breast cancer? Br J Cancer 2009, 101(3):403-409.

4. Lilla C, Ambrosone CB, Kropp S, Helmbold I, Schmezer P, von Fournier D, Haase W, Sautter-Bihl ML, Wenz F, Chang-Claude J: Predictive factors for late normal tissue complications following radiotherapy for breast cancer. Breast Cancer Res Treat 2007, 106(1):143-150.

5. Keller LMM, Sopka DM, Li TY, Klayton T, Li JS, Anderson PR, Bleicher RJ, Sigurdson ER, Freedman GM: Five-year results of whole breast intensity modulated radiation therapy for the treatment of early stage breast cancer: the fox chase cancer center experience. Int J Radiat Oncol Biol Phys 2012, 84(4):881-887.

6. Pignol JP, Olivotto I, Rakovitch E, Gardner S, Sixel K, Beckham W, Vu TT, Truong P, Ackerman I, Paszat L: A multicenter randomized trial of breast intensity-modulated radiation therapy to reduce acute radiation dermatitis. J Clin Oncol 2008, 26(13):2085-2092.

7. Freedman GM, Anderson PR, Li JS, Eisenberg DF, Hanlon AL, Wang L, Nicolaou N: Intensity modulated radiation therapy (IMRT) decreases acute skin toxicity for women receiving radiation for breast cancer. Am J Clin Oncol-Cancer Clinical Trials 2006, 29(1):66-70.

8. Moody AM, Mayles WPM, Bliss JM, Ahern RP, Owen JR, Regan J, Broad B, Yarnold JR: The influence of breast size on late radiation effects and association with radiotherapy dose inhomogeneity. Radiother Oncol 1994, 33(2):106-112

9. Talbot CJ, Tanteles GA, Barnett GC, Burnet NG, Chang-Claude J, Coles CE, Davidson S, Dunning AM, Mills J, Murray RJS, Popanda O, Seibold P, West CML, Yarnold JR, Symonds RP: A replicated association between polymorphisms near TNF alpha and risk for adverse reactions to radiotherapy. Br J Cancer 2012, 107(4):748-753.

10. Kim JH, Kolozsvary AJJ, Jenrow KA, Brown SL: Mechanisms of radiation-induced skin injury and implications for future clinical trials. Int J Radiat Biol 2013, 89(5):311-318.

11. Rosenstein BS: Identification of SNPs associated with susceptibility for development of adverse reactions to radiotherapy. Pharmacogenomics 2011, 12(2):267-275.

12. Murray RJS, Tanteles GA, Mills J, Perry A, Peat I, Osman A, Chan S, Cheung KL, Chakraborti PR, Woodings PL, Barwell JG, Symonds RP, Talbot CJ: Association between single nucleotide polymorphisms in the DNA repair 
gene LIG3 and acute adverse skin reactions following radiotherapy. Radiother Oncol 2011, 99(2):231-234.

13. Suga T, Ishikawa A, Kohda M, Otsuka Y, Yamada S, Yamamoto N, Shibamoto Y, Ogawa Y, Nomura K, Sho K, Omura M, Sekiguchi K, Kikuchi Y, Michikawa Y, Noda S, Sagara M, Ohashi J, Yoshinaga S, Mizoe J, Tsuiti H, Iwakawa M, Imai T: Haplotype-based analysis of genes associated with risk of adverse skin reactions after radiotherapy in breast cancer patients. Int J Radiat Oncol Biol Phys 2007, 69(3):685-693.

14. Werbrouck J, De Ruyck K, Duprez F, Veldeman L, Claes K, Van Eijkeren M, Boterberg T, Willems P, Vral A, De Neve W, Thierens H: Acute normal tissue reactions in head-and-neck cancer patients treated with Imrt: influence of dose and association with genetic polymorphisms in DNA Dsb repair genes. Int J Radiat Oncol Biol Phys 2009, 73(4):1187-1195.

15. Worrillow $L$, Smith AG, Scott K, Andersson M, Ashcroft AJ, Dores GM, Glimelius B, Holowaty E, Jackson GH, Jones GL, Lynch CF, Morgan G, Pukkala E, Scott D, Storm HH, Taylor PR, Vyberg M, Willett E, Travis LB, Allan JM: Polymorphic MLH1 and risk of cancer after methylating chemotherapy for Hodgkin lymphoma. J Med Genet 2008, 45(3):142-146.

16. Smirnov DA, Morley M, Shin E, Spielman RS, Cheung VG: Genetic analysis of radiation-induced changes in human gene expression. Nature 2009, 459(7246):587-U120

17. Mulliez T, Speleers B, Madani I, De Gersem W, Veldeman L, De Neve W: Whole breast radiotherapy in prone and supine position: is there a place for multi-beam IMRT? Radiat Oncol 2013, 8:151.

18. Bentzen SM, Agrawal RK, Aird EGA, Barrett JM, Barrett-Lee PJ, Bliss JM, Brown J, Dewar JA, Dobbs HJ, Haviland JS, Hoskin PJ, Hopwood P, Lawton PA, Magee BJ, Mills J, Morgan DAL, Owen JR, Simmons S, Sumo G, Sydenham MA, Venables K, Yarnold JR, Start Trialists G: The UK Standardisation of Breast Radiotherapy (START) Trial B of radiotherapy hypofractionation for treatment of early breast cancer: a randomised trial. Lancet 2008, 371(9618):1098-1107.

19. Mulliez T, Veldeman L, van Greveling A, Speleers B, Sadeghi S, Berwouts $D$, Decoster F, Vercauteren T, De Gersem W, Van den Broecke R, De Neve W: Hypofractionated whole breast irradiation for patients with large breasts: A randomized trial comparing prone and supine positions. Radiother Oncol 2013, 108(2):203-208.

20. Remouchamps VM, Vicini FA, Sharpe MB, Kestin LL, Martinez AA, Wong JW: Significant reductions in heart and lung doses using deep inspiration breath hold with active breathing control and intensity-modulated radiation therapy for patients treated with locoregional breast irradiation. Int J Radiat Oncol Biol Phys 2003, 55(2):392-406.

21. Menashe I, Rosenberg PS, Chen BE: PGA: power calculator for case-control genetic association analyses. BMC Genet 2008, 9:36

22. James ML, Lehman M, Hider PN, Jeffery M, Hickey BE, Francis DP: Fraction size in radiation treatment for breast conservation in early breast cancer. Cochrane Database Syst Rev 2010, (11):CD003860.

23. Hannan R, Thompson RF, Chen Y, Bernstein K, Kabarriti R, Skinner W, Chen CC, Landau E, Miller E, Spierer M, Hong L, Kalnicki S: Hypofractionated whole-breast radiation therapy: does breast size matter? Int I Radiat Oncol Biol Phys 2012, 84(4):894-901.

24. Corbin KS, Dorn PL, Jain SK, Al-Hallaq HA, Hasan Y, Chmura SJ: Hypofractionated radiotherapy does not increase acute toxicity in large-breasted women: results from a prospectively collected series. Am J Clin Oncol 2014, 37(4):322-326.

25. Goldsmith C, Haviland J, Tsang Y, Sydenham M, Yarnold J, Grp FT: Large breast size as a risk factor for late adverse effects of breast radiotherapy: Is residual dose inhomogeneity, despite 3D treatment planning and delivery, the main explanation? Radiother Oncol 2011, 100(2):236-240.

26. Barnett GC, Wilkinson JS, Moody AM, Wilson CB, Twyman N, Wishart GC, Burnet NG, Coles CE: The cambridge breast intensity-modulated radiotherapy trial: patient- and treatment-related factors that influence late toxicity. Clin Oncol 2011, 23(10):662-673.

27. Dorn PL, Corbin KS, Al-Hallag H, Hasan Y, Chmura SJ: Feasibility and acute toxicity of hypofractionated radiation in large-breasted patients. Int $J$ Radiat Oncol Biol Phys 2012, 83(1):79-83.

28. Azria D, Belkacemi Y, Romieu G, Gourgou S, Gutowski M, Zaman K, Moscardo CL, Lemanski C, Coelho M, Rosenstein B, Fenoglietto P, Crompton NEA, Ozsahin M: Concurrent or sequential adjuvant letrozole and radiotherapy after conservative surgery for early-stage breast cancer (CO-HO-RT): a phase 2 randomised trial. Lancet Oncol 2010, 11(3):258-265.
29. Halyard MY, Pisansky TM, Dueck AC, Suman V, Pierce L, Solin L, Marks L, Davidson N, Martino S, Kaufman P, Kutteh L, Dakhil SR, Perez EA: Radiotherapy and adjuvant trastuzumab in operable breast cancer: tolerability and adverse event data from the NCCTG Phase III Trial N9831. J Clin Oncol 2009, 27(16):2638-2644.

30. Whiffin N, Broderick P, Lubbe SJ, Pittman AM, Penegar S, Chandler I, Houlston RS: MLH1-93G > A is a risk factor for MSI colorectal cancer. Carcinogenesis 2011, 32(8):1157-1161.

31. Janko M, Ontiveros F, Fitzgerald TJ, Deng A, DeCicco M, Rock KL: IL-1 Generated subsequent to radiation-induced tissue injury contributes to the pathogenesis of radiodermatitis. Int J Radiat Oncol Biol Phys 2012, 84(3):S679-5679.

doi:10.1186/1471-2407-14-711

Cite this article as: De Langhe et al.: Factors modifying the risk for developing acute skin toxicity after whole-breast intensity modulated radiotherapy. BMC Cancer 2014 14:711.

\section{Submit your next manuscript to BioMed Central and take full advantage of:}

- Convenient online submission

- Thorough peer review

- No space constraints or color figure charges

- Immediate publication on acceptance

- Inclusion in PubMed, CAS, Scopus and Google Scholar

- Research which is freely available for redistribution

Submit your manuscript at www.biomedcentral.com/submit
C BioMed Central 